\title{
Grouting Fractured Coal Permeability Evolution Based on Industrial CT Scanning
}

\author{
Li Tao, ${ }^{1,2,3}$ Yao Banghua $\mathbb{D}^{3,4}$ Liu Yong $\mathbb{D}^{3,4}$ and Wang Dengke ${ }^{3,4}$ \\ ${ }^{1}$ School of Emergency Management and Safety Engineering, China University of Mining \& Technology-Beijing, Beijing 100083, China \\ ${ }^{2}$ School of Electrical Engineering \& Automation, Henan Polytechnic University, Jiaozuo 454000, China \\ ${ }^{3}$ State Collaborative Innovation Center of Coal Work Safety and Clean-Efficiency Utilization, Jiaozuo 454000, China \\ ${ }^{4}$ School of Safety Science and Engineering, Henan Polytechnic University, Jiaozuo 454000, China
}

Correspondence should be addressed to Yao Banghua; yaobanghua@126.com

Received 11 January 2021; Revised 17 February 2021; Accepted 5 March 2021; Published 17 March 2021

Academic Editor: Yi Xue

Copyright (c) $2021 \mathrm{Li}$ Tao et al. This is an open access article distributed under the Creative Commons Attribution License, which permits unrestricted use, distribution, and reproduction in any medium, provided the original work is properly cited.

\begin{abstract}
Gas extraction from coal seams in China faces various middle-term and long-term problems, such as the poor sealing quality and low extraction rate. The mean gas extraction concentration is only $30 \%$. Studying the flowing laws of the grout and fracture plugging mechanism is of important significance to improve the sealing quality and increase the gas extraction efficiency. For this reason, a new coal-based grouting material was prepared in this study, and its parameters such as viscosity were tested. Moreover, a grouting theoretical model with considerations of the flowing of the grout and coal fracture plugging by migration and deposition of slurry particles was constructed. The crack distribution before and after the grouting of fractured coal samples was scanned with an industrial CT, and the fracture distribution of coal samples was reconstructed using an independently compiled MATLAB program. Meanwhile, the variations of the coal permeability before and after the grouting were tested. On this basis, this study built a numerical calculation model of the grouting in fractured coal samples to simulate the leakage stoppage and permeability reduction mechanism of the coal-based sealing material grouting. Results demonstrate that (1) according to the experimental test results, the new coal-based grouting materials achieve a good fracture plugging effect, and the fractures in coal samples after the grouting are filled densely by the grouting particles. (2) According to the simulation results, the permeability of grouting coal samples declines quickly and then tends to be stable. The overall permeability of coal samples and the fracture permeability are decreased by $93.5 \%$ and more than $99.9 \%$ in average, respectively. (3) Influences of the grouting pressure on the permeability variation of coal samples were investigated through a numerical simulation. It was found that a reasonable grouting pressure for coal samples is about $0.3 \mathrm{MPa}$. (4) The numerical simulation reproduces the whole process of the grout flowing and the fracture filling. The variation laws of the diffusion and the permeability of the grout which are calculated through a numerical simulation agree well with the experimental results, which verifies the reasonability of the model. Research conclusions can provide important significance in theory and practice to disclose the leakage stoppage and the permeability reduction mechanism of the borehole grouting during the gas extraction and strengthen the sealing effects of extraction boreholes.
\end{abstract}

\section{Introduction}

With the vertical extension of coal mining in China, disasters like coal and gas outburst are intensifying increasingly. Gas extraction is an important technical mean to develop and use gas resources and prevent gas disaster accidents in coal mines $[1,2]$. Nevertheless, gas extraction from coal seams generally has low extraction efficiency in China, and the mean gas extraction concentration is only $30 \%$ [3]. This is because due to the general poor sealing quality, a lot of air in the roadway enters into the borehole along the surrounding rock fractures under the effect of negative extraction pressure, thus causing air leakage (Figure 1). At present, the grouting sealing technique like "two-plugging and onegrouting" is a common sealing technique in gas extraction [1]. The principle of "two-plugging and one-grouting" is to 


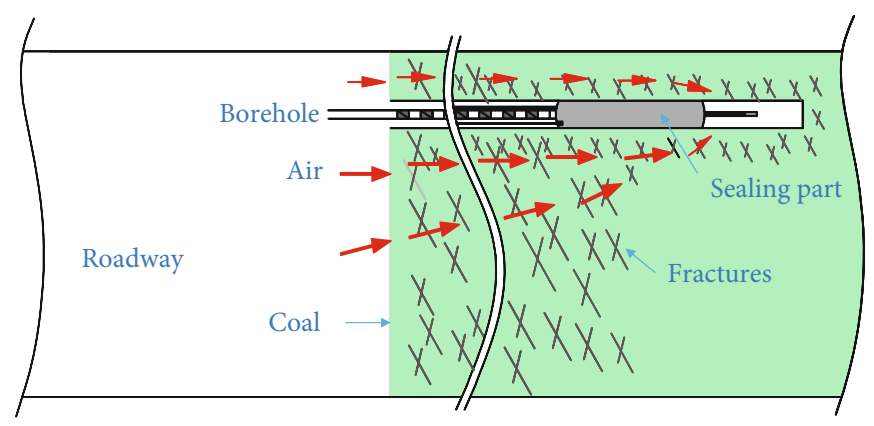

FIgURE 1: Air leakage in boreholes for gas extraction.

inject some condensable grout into the fractures or pores of coal mass to improve the physical and mechanical properties of coal masses and thereby increase their antipermeability and stability [4-6]. Therefore, exploring the flowing and diffusion laws of grout and fracture sealing mechanism of coal masses has important engineering significance to guide the sealing effect of boreholes and increase the gas extraction efficiency.

With respect to existing studies on the flowing and diffusion laws of grout, scholars have developed a grouting theory of rock masses with boreholes, a grouting theory of fractured rock masses, a splitting grouting theory, a compaction grouting theory, and a dynamic grouting theory [7-11]. With respect to the grouting theory of fractured rock masses, Baker deduced a flow equation of Newtonian fluid in fractures under the assumption that the fractures are parallel smooth fractures with equal widths $[12,13]$. Mu et al. [14] established a grout diffusion model in a single random fracture. Xiao et al. [15] calculated the relation curve between the extension distance of grout in fractures of a panel and the grouting time. Based on the flowing theory of viscous fluid, Xiaolong et al. [16] built a radial diffusion model of grout in singleplane fracture under anhydrous conditions. Gustafson et al. [8] assumed that the grouting pressure is a constant value and studied the flowing law of grout in a single-plane fracture based on the Bingham body constitutive model. Draganović et al. [17] developed a short-slot model between two assembled discs with constrictions to investigate the filtration and penetration length of cement-based grout. Yang et al. [18] carried out a numerical simulation study on the diffusion process of cement-based grout with a single rough crack through a finite element method. Saeidi et al. [19] studied the influences of crack characteristics on grout flowing and penetration length in fractured rock masses through a numerical simulation based on discrete element software (Udec). Wenjun [20] built a diffusion and flow model of the route in fractured rock masses with consideration of the variations of the viscosity of the grout with time. With consideration of time-varying characteristics of the viscosity of grout, Qingsong et al. [21] constructed a theoretical model of grout diffusion in horizontal fractures under a constant grouting speed.

The sealing effect of grout in fractured rock masses is mainly reflected by the changes of fracture and permeability. With respect to studies on the permeability of grouting rock masses, Renshu et al. [22] analyzed the fracture variations of mudstone samples before and after grouting through CT scanning under laboratory conditions and evaluated the fracture sealing effect by a method based on fractal dimension. Yue [23] tested the permeability of coal samples after grouting and carried out an intuitive analysis of the influences of grouting viscosity on the sealing effect of coal mass. Ning et al. [24] carried out a numerical simulation study of the variation laws of permeability of rock masses after grouting. Based on an independently developed large triaxial seepagegrouting multifunctional platform, Qi et al. [25] investigated the evolutionary characteristics of the permeability of rock masses before and after grouting through an experiment. Rentai et al. [26] gained the relationship between the fracture of rock masses and osmotic coefficient through a drilling analysis, analyzed the flowing law of grout during the grouting process through the flow dimension theory, and evaluated the sealing effect of rock grouting. Guangxuan et al. [27] developed an experimental system of 3-dimensional penetrating grouting model and implemented a grouting test on sandstone samples, getting time-varying laws of porosity, permeability, and grouting pressure of samples. Sun et al. [28] proposed a coupling HM model based on the coupling effect between grout and rock mass and discussed the grouting process through a numerical simulation. Moreover, they analyzed the influences of geostress on anisotropic permeability characteristics of grouting rock masses. $\mathrm{Xu}$ et al. [29] discussed the leakage stoppage and permeability reduction of grouting in deep-fractured rock masses through an independently developed physical simulation platform of grouting.

In the above studies, the mathematical model of describing the diffusion and flow laws of grout is mature. Associated studies have made beneficial discussions on the flowing and diffusion laws and sealing effect of grout. However, most of the existing studies assume coal and rock masses as an ideal isotropic body [30-33] or set the fracture distribution based on a random function [34]. Uncertainty of the initial fracture distribution influences the reliability of the calculation results directly, thus making existing studies difficult to describe the motion law and diffusion scope of grout accurately. Moreover, the associated studies hardly have considered the physical essence of fracture and permeability changes of coal and rock masses caused by sedimentation of grout particles, and they cannot predict the leakage stoppage and permeability 


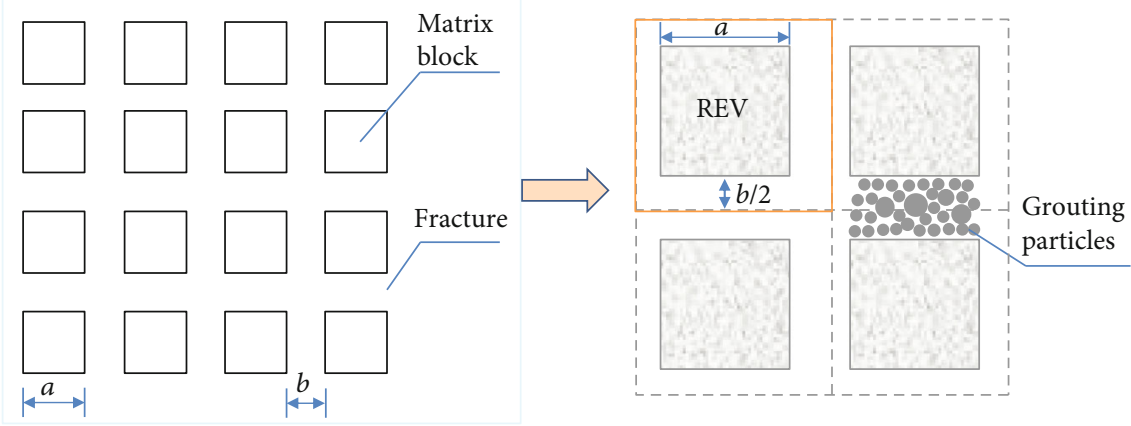

Figure 2: Sketch of the physical model for broken coal with grouting.

reduction characteristics of grout in coal samples reliably. Furthermore, it lacks of a systematic study on flowing characteristics and performance in leakage stoppage and permeability reduction of the new coal-based grouting material. Based on the distribution law of fracture field in coals which was gained from practical CT scanning, this study reflected the fracture evolution seepage law of grout in coal masses scientifically with considerations to the fracture evolution, leakage stoppage, and permeability reduction mechanism of grouting caused by diffusion deposition of grouting particles. Research conclusions lay the foundation for the optimization of grouting-based sealing of boreholes during gas extraction. This study has important theoretical and practical significance.

\section{Theoretical Grouting-Based Sealing Model of Surrounding Rock Fractures}

Through grouting of fractured coal and rock masses, the grout is driven by the grouting pressure and flows along fractures in coal masses. Grouting particles deposit in block the fractures, thus influencing the permeability of coal mass. To establish an evolutionary model of the permeability of fractured coal masses after grouting, some basic hypotheses were set up:

(1) Grouting particles are incompressible, and the injection concentration remains constant

(2) Effects of stress changes on the fractures of coal mass are ignored in the grouting process

(3) The deposition process of grouting particles is irreversible. In other words, the separation process of deposited grouting particles is ignored.

2.1. Definition. Based on the aforementioned assumptions, a representative element for a typical coal microstructure is shown in Figure 2. The length $L(\mathrm{~m})$ and volume $V(\mathrm{~m} 3)$ of the element are expressed as

$$
\begin{aligned}
& L=a+b, \\
& V=(a+b)^{3},
\end{aligned}
$$

where $a(\mathrm{~m})$ is the length of the matrix and $b(\mathrm{~m})$ is the aperture of the fracture.
The total voidage $\varphi(\%)$ of an element is written as

$$
\varphi=\frac{(a+b)^{3}-a^{3}}{(a+b)^{3}} \cong \frac{3 b}{a} .
$$

It should be noted that $b \ll a$.

2.2. Mass Conservation Equations for Particles. To study the sediment characteristics of the grouting particles, the dynamic mass conservation equations for the particles were calculated based on a three-dimensional representative element, as illustrated in Figure 3.

Grouting particles have migration and sediment processes inside a representative element. For the migration process, the average seepage velocity of an element can be defined as $\vec{q}_{i}(\mathrm{~m} / \mathrm{s})$. In the direction of $x_{i}(i=1,2,3)$, the mass increase of particles flowing into the element in a unit time can be calculated as

$$
-\frac{\partial\left(C \rho_{s} q_{i}\right)}{\partial x_{i}} V
$$

where $C(\%)$ is the particle concentration (i.e., particle saturation) and $\rho s(\mathrm{~kg} / \mathrm{m} 3)$ denotes the density of grouting particles.

Figure 3 Illustration of a three-dimensional characteristic element. $M_{i}$ is the mass change of solids due to convection, defined as $M_{i}=C \rho_{s} q_{i}$.

In the direction of $x_{i}$, the mass flowing into the element due to the sediment should be expressed as

$$
-\frac{\partial M_{i}}{\partial x_{i}} V(i=1,2,3) .
$$

For the element, the total mass flowing can be expressed as the summation of the three directions:

$$
-\sum_{i=1}^{3}\left(\frac{\partial M_{i}}{\partial x_{i}} V\right)
$$

For the sediment process, the total mass flowing into the element can be expressed as

$$
-\frac{\partial \varphi}{\partial t} \rho_{s} V
$$




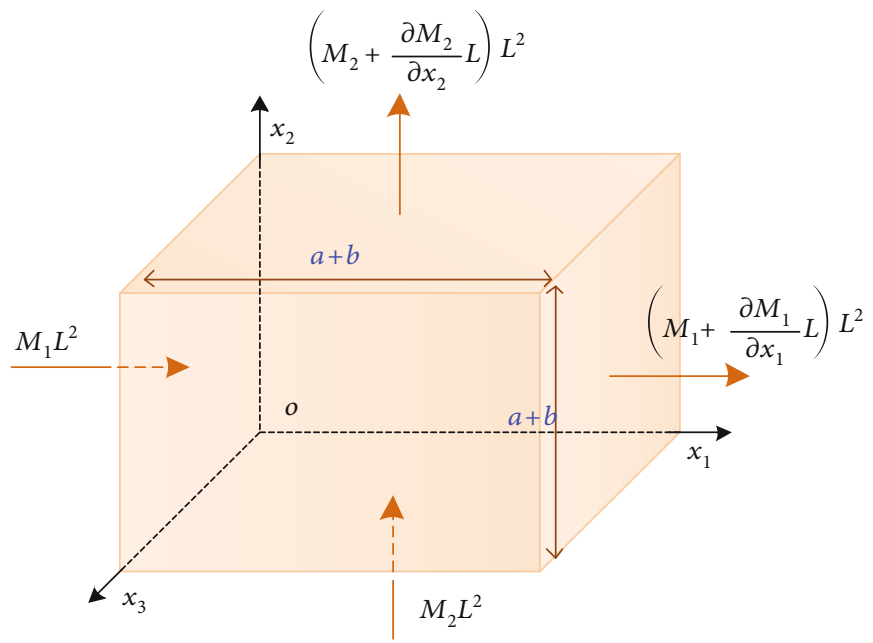

FIGURE 3: Sketch of a representative element for broken coal.

According to the mass conservation law for the unit element, giving the mass conservation equation for particles as

$$
\frac{\partial}{\partial t}\left(C \varphi \rho_{s}\right) V=-\sum_{i=1}^{3}\left(\frac{\partial M_{i}}{\partial x_{i}} V\right)-\frac{\partial \varphi}{\partial t} \rho_{s} V
$$

Equation (8) can be simplified as

$$
\frac{\partial}{\partial t}(C \varphi)+\nabla \cdot(C \vec{q})=-\frac{\partial \varphi}{\partial t}
$$

2.3. Water Mass Conservation Equations. In a similar way as Equation (9), the mass conservation equation for water flow can be derived as

$$
\frac{\partial[\varphi(1-C)]}{\partial t}+\nabla \cdot[(1-C) \vec{q}]=0
$$

2.4. Evolution of the Fracture Aperture and Permeability. According to that study $[35,36]$, the evolution of fracture aperture was affected by the particles concentration as well as the seepage velocity. The following equations have been developed to determine the evolution of the fracture aperture:

$$
\begin{aligned}
\frac{\partial \varphi}{\partial t} & =C \cdot K_{d e p}, \\
K_{d e p} & =\frac{3(1-\varphi) u}{2 D_{c}} \eta .
\end{aligned}
$$

The relationship between element permeability and fracture aperture can be expressed as

$$
\begin{gathered}
k=\frac{b^{3}}{12 a}, \\
\frac{k}{k_{0}}=\left(\frac{b}{b_{0}}\right)^{3} .
\end{gathered}
$$

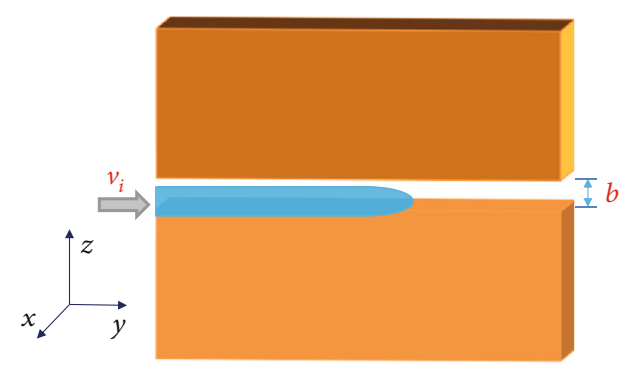

FIGURE 4: Sketch of grouting flow in coal fracture.

2.5. Grout Flow. The schematic diagram of the flow of grouting slurry in the coal cracks is shown in Figure 4. According to the related study [37], the velocity equation describing the flow of grout can be obtained:

$$
q_{i}=-\frac{k}{\eta} \nabla p_{i}\left(1-\frac{\lambda}{\left|\nabla p_{i}\right|}\right)
$$

where

$$
\lambda=\frac{4 \tau_{s}}{b} .
$$

$\tau_{s}$ is the yield stress of the grouting slurry, which can be obtained by the test.

Equations (9)-(16) compose the coupled processes of coal fracture grouting under sediment effects. The above governing equations will be implemented into COMSOL Multiphysics next to understand the grouting mechanism in coal fractures.

\section{Grouting Test of Fractured Coal Samples}

3.1. Preparation of Grout and Viscosity Test. It can be seen from Figure 5 that a new grouting material was prepared by water, curing agent, expansive agent, and coal powder with grain size lower than 100 meshes. Grout samples with different water-solid ratios were prepared, and variations of their 


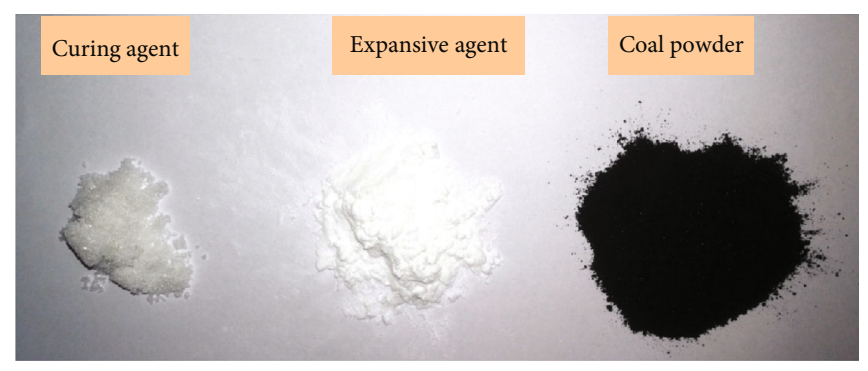

FIGURE 5: Raw materials of grouting.

Table 1: Proportioning scheme of water-solid ratio.

\begin{tabular}{lcccc}
\hline $\begin{array}{l}\text { Water-solid } \\
\text { ratio }\end{array}$ & $\begin{array}{c}\text { Mass of coal } \\
\text { powder }(\mathrm{g})\end{array}$ & $\begin{array}{c}\text { Curing } \\
\text { agent }(\mathrm{g})\end{array}$ & $\begin{array}{c}\text { Expansive } \\
\text { agent }(\mathrm{g})\end{array}$ & $\begin{array}{c}\text { Water } \\
(\mathrm{g})\end{array}$ \\
\hline 0.5 & 500 & 2 & 400 & 451 \\
0.8 & 500 & 2 & 400 & 721.6 \\
0.9 & 500 & 2 & 400 & 811.8 \\
1 & 500 & 2 & 400 & 902 \\
1.5 & 500 & 2 & 400 & 1353 \\
2 & 500 & 2 & 400 & 1804 \\
\hline
\end{tabular}

viscosities were tested by experiments. The proportioning schemes of water-solid ratio are shown in Table 1.

We test the viscosity of grout samples by using a Brinell viscosity rotation tester, and the time-varying test results and fitting curves of viscosity of grout samples with different water-solid ratios are shown in Figure 6. Clearly, the initial apparent viscosity is negatively correlated with water-solid ratio. This is because the internal frictional resistance of the grout decreases with the increase of free water content in the grout. Moreover, the apparent viscosity of grout samples with different water-solid ratios presents an upward trend as time goes on, because the grout samples condense gradually and the internal frictional resistance increases accordingly.

3.2. Experimental System and Steps. Grouting and experimental systems of fractured coal samples are shown in Figure 7. It is mainly composed of three experimental systems, namely, permeability test system, CT scanning system, and grouting test system. The permeability test system is to measure the permeability of coal samples before grouting. The CT scanning system is to acquire the initial fracture distribution in coal samples through CT scanning and then carry out a grouting test of coal samples: (1) coal samples were wrapped with silicon seals and then loaded into a closed cavity. The lower valve was kept open. (2) The upper valve was connected to the grouting pipeline, and it was kept open. (3) The prepared grouting materials were added by a manual pressure pump and then the grouting test began. (4) In the grouting test, the grouting pressure was maintained at $0.2 \mathrm{MPa}$, and the upper valve was closed at $30 \mathrm{~min}$. The grouting pipeline and manual pressure pump were cleaned. (5) The closed cavity was open, and coal samples were taken out. The grouting air chamber was cleaned for later use. After finishing the grouting process, the permeability test and CT scanning test of coal samples were performed again.
3.3. Experimental Results and Analysis. CT scanning results of coal sample $1 \#$ before and after grouting are shown in Figure 8. It can be seen from Figure 8(a) that the main fractures extend gradually from the upper to bottom of the coal samples, and the fractures are relatively wide. In this process, fractures incline toward one side, and two fractures which could extend to other sides could be seen at the upper end and at $1 / 3$ of the coal samples. The width of these two fractures was relatively low. The main fracture developed two branches after reaching the middle position of the coal samples. One branch stops extension after reaching one side surface, and the other branch was twisted after reaching the side surface and then extended to the lower position of coal samples. This branch was relatively narrow, and it only could be seen from images. In Figure 9(b), the main fracture of coal samples was filled completely by the grouting material. In branch fractures, grouting materials cannot run through the whole fracture channel due to the small width, big sinuosity, and poor connectivity. There are few grouting particles in branches.

CT scanning results of coal sample $2 \#$ before and after grouting are shown in Figure 9. It can be seen from Figure $9(\mathrm{a})$ that there is a big fracture on the upper position of the coal sample. It extends from top to bottom, then inclines toward the side surface after reaching $1 / 3$ of the upper position of the coal sample, and finally disappears. No other evident fracture structure is found in the coal samples. However, white minerals form a dense distribution at $1 / 3$ of the lower position of the coal sample. Figure 9(b) shows that the fracture shows good connectivity, and it is filled completely by the grout, forming good cementation between the grouting materials and the fracture wall.

With reference to the permeability test of coal samples [38-43], the permeability of coal samples before and after grouting was tested through a triaxial gas seepage experimental system of coal and rock masses. Test conditions and results are listed in Table 2. Clearly, permeability of coal samples after grouting declines significantly compared to the initial value. The permeability of coal samples $1 \#$ and $2 \#$ is decreased by $93.0 \%$ and $95.5 \%$, respectively.

\section{Numerical Modeling of Grouting in Fractured Coal Masses}

4.1. Construction of a Numerical Model. In the above experiments, coal samples before grouting were scanned using an industrial CT, through which the internal fracture distribution of coal mass was gained. It can be seen from 


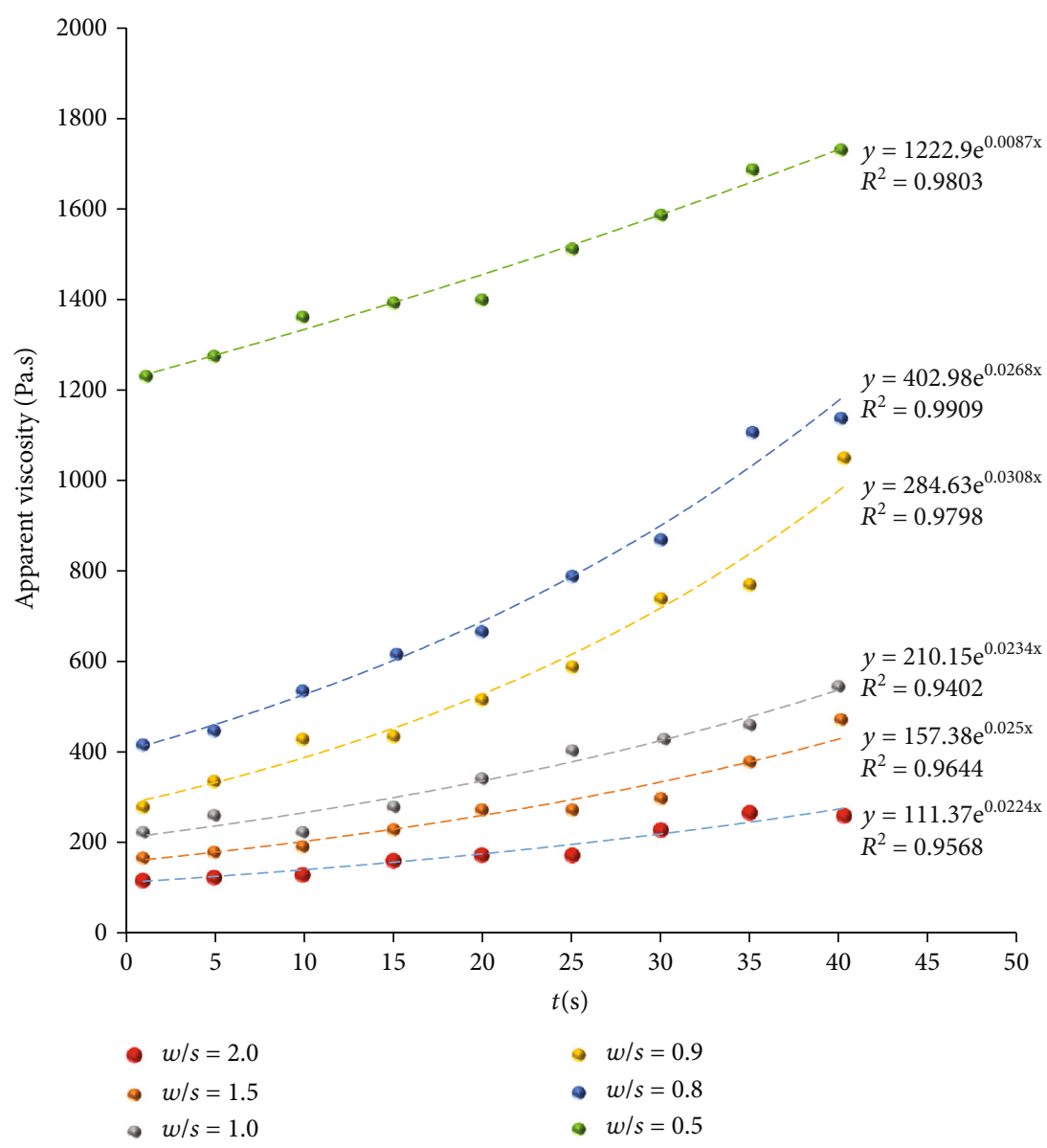

Figure 6: Time-varying curves of viscosity of grout samples with different water-solid ratios.
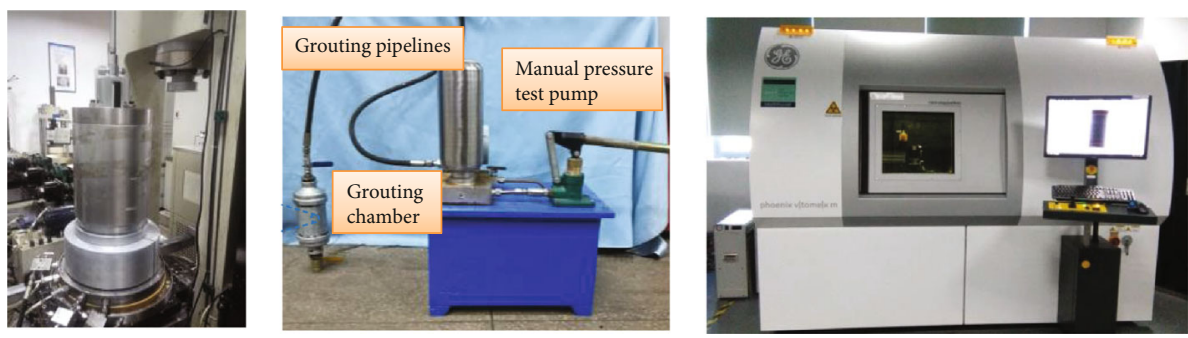

FIgURE 7: Experimental systems.

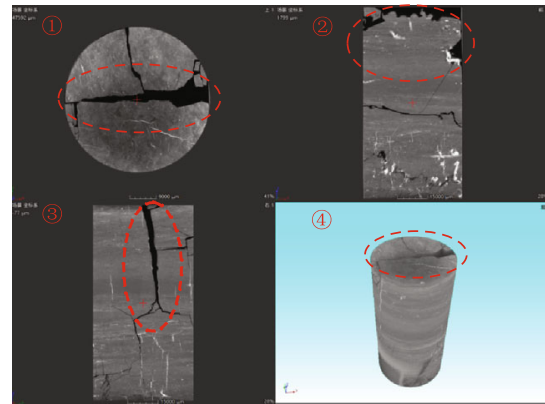

(a)

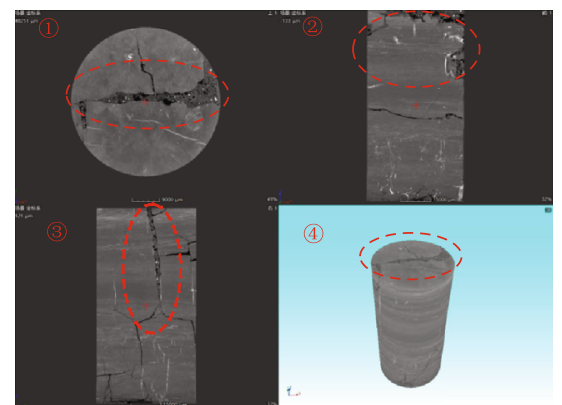

(b)

FIGURE 8: CT scanning results of coal sample 1\#: (a) before grouting, (b) after grouting. 


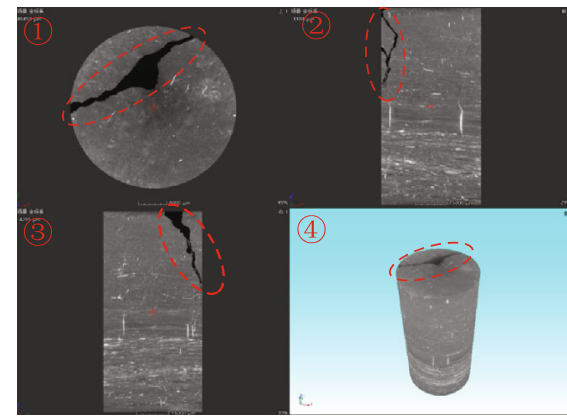

(a)

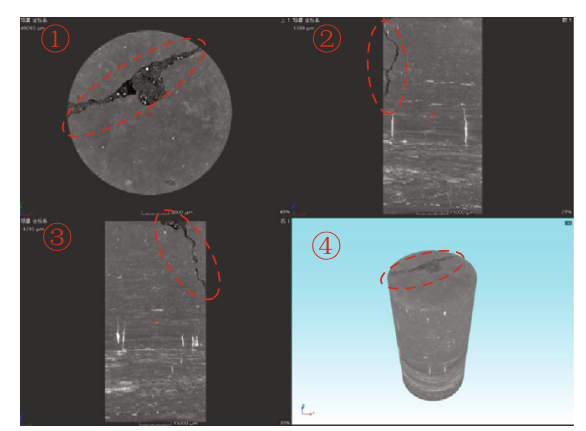

(b)

FIgURE 9: CT scanning results of coal sample 2\#: (a) before grouting, (b) after grouting.

TABLE 2: Variations of permeability of coal samples before and after grouting.

\begin{tabular}{lccc}
\hline No. & $\begin{array}{c}\text { Initial permeability } \\
\left(k_{0} / \mathrm{mD}\right)\end{array}$ & $\begin{array}{c}\text { Permeability } \\
\text { after grouting } \\
\left(k_{1} / \mathrm{mD}\right)\end{array}$ & $\begin{array}{c}\text { Reduction } \\
\left(k_{0}-k_{1}\right) / k_{0}\end{array}$ \\
\hline 1 & $37.0 \mathrm{mD}$ & $2.6 \mathrm{mD}$ & $93.0 \%$ \\
2 & $6.7 \mathrm{mD}$ & $0.3 \mathrm{mD}$ & $95.5 \%$ \\
\hline
\end{tabular}

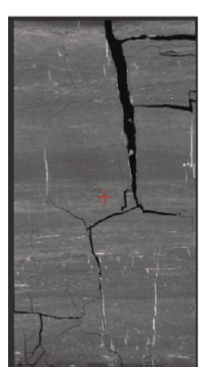

(a)

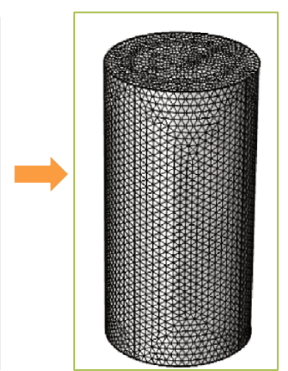

(b)

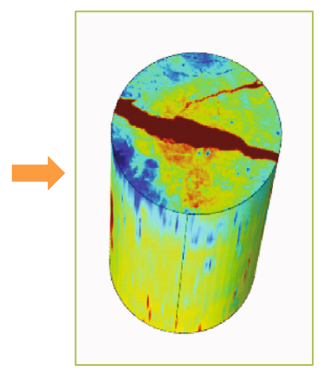

(c)
Figure 10: Numerical calculation model of grouting in fractured coal samples. (a) CT scanning fracture. (b) Model meshing. (c) Numeralization fracture distribution.

Figure 10(a) that the diameter and height of coal samples were set $50 \mathrm{~mm}$ and $100 \mathrm{~mm}$, respectively. A numerical calculation model which was consistent with the dimension of coal samples was built (Figure 10(b)), in which the mesh generation is tetrahedral mesh, and the number is about 80000 . Boundary conditions for numerical simulation were set according to the experimental conditions. Specially, the grouting pressures on the upper surface and lower surface of coal samples were set as $0.2 \mathrm{MPa}$ and 0 , respectively. There were no permeable boundaries surrounding the coal samples. Initial condition is as follows: the initial grout concentration of the model was 0 , and CT scanning slices of coal samples were processed by the independently compiled MATLAB program. The generated documents were input into a finite element numerical simulation software COMSOL, getting the initial fracture distribution diagram of coal samples. In Figure $10(\mathrm{c})$, the initial permeability distribution of coal samples was gained by combining the permeability test results of coal samples based on the above results. Main parameters of numerical simulation are listed in Table 3.

\subsection{Numerical Simulation Results and Analysis}

4.2.1. Grouting Pressure. The cloud maps of the variation of grouting pressure in coal samples $1 \#$ and $2 \#$ with time are shown in Figures 11 and 12, respectively. As the grouting process continues, the grouting pressure of coal samples diffuses gradually from top to bottom. Pressure distribution runs through the coal samples at $200 \mathrm{~s}$, indicating that the grout flows from the lower end to the upper end of the coal samples. Pressure in fractures tends to be stable after $2000 \mathrm{~s}$. It also can be seen that the grouting pressure in coal sample 1 \# diffuses relatively slowly, and the pressure in the end fracture has not reached the maximum at $200 \mathrm{~s}$. By combining with CT scanning maps, this is the consequence of wide fractures and good permeability on the upper surface of coal samples, but narrow fractures and poor permeability on the lower surface of coal samples. Grouting pressure diffuses quickly in coal sample $2 \#$ due to the short fracture, and the pressure was stable at $100 \mathrm{~s}$.

4.2.2. Permeability of Coal Samples. The cloud maps of permeability variations of coal samples $1 \#$ and $2 \#$ with time are shown in Figures 13 and 14. Clearly, the permeability at the fracture of coal samples is far higher than that in the nonfractured zones in the beginning of grouting. As grouting continues, the fractures are filled by the grout, and the permeability declines continuously. Permeability at the fracture of coal masses is similar to that in the nonfractured zones after $2000 \mathrm{~s}$. Besides, the fracture on the upper end of coal samples is blocked firstly in the grouting process, and the permeability declines quickly. As the grout diffuses downward continuously, the permeability at the lower position of coal samples decreases gradually. Finally, the fractures that run through the coal samples are filled by grout. Specifically, the permeability in the upper section of the fracture of coal sample 1\# decreases quickly, while the permeability at the lower branch of the fracture decreases slowly. This is attributed to the small width of the branch and the slow flowing of the grout. Similar phenomenon of permeability variation is observed for the coal sample 2\#. The slow reduction of permeability in the lower section of the fracture is attributed to 
TABLE 3: Main parameters for simulation.

\begin{tabular}{lcccccc}
\hline $\begin{array}{l}\text { Grout density } \\
\mathrm{kg} \mathrm{m}^{-3}\end{array}$ & $\begin{array}{c}\text { Grouting pressure } \\
\mathrm{MPa}\end{array}$ & Water-solid ratio & $\begin{array}{c}\text { Viscosity } \\
\mathrm{Pa} \mathrm{s}\end{array}$ & $\begin{array}{c}\text { Sedimentation coefficient } \\
\mathrm{h}^{-1}\end{array}$ & $\begin{array}{c}a \\
\mathrm{~m}\end{array}$ & $\begin{array}{c}\text { Yield stress } \\
\mathrm{MPa}\end{array}$ \\
\hline 1340 & 0.2 & 1.5 & $\eta=154.55 \mathrm{e}^{0.0254 \mathrm{t}}$ & 80 & 0.1 & 55.6 \\
\hline
\end{tabular}

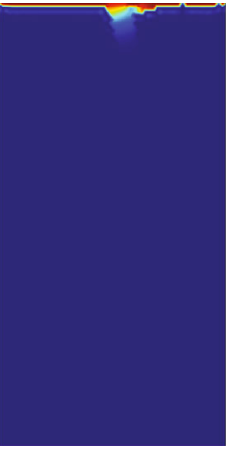

(a)

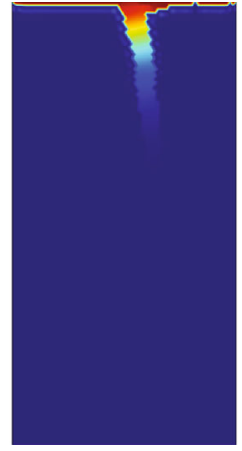

(b)

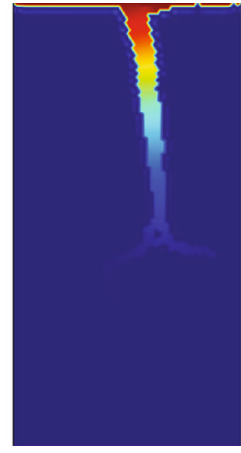

(c)

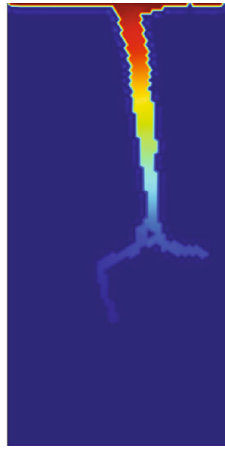

(d)

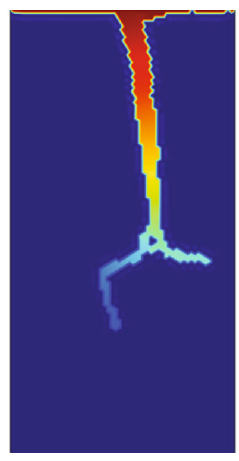

(e)

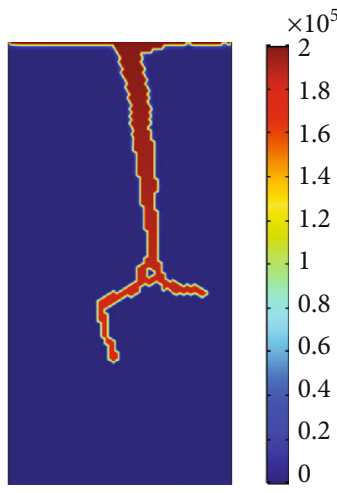

(f)

Figure 11: Cloud map of the variation of grouting pressure distribution with time (coal sample 1\#). (a) $t=1 \mathrm{~s}$. (b) $10 \mathrm{~s}$. (c) $50 \mathrm{~s}$. (d) $100 \mathrm{~s}$. (e) $200 \mathrm{~s}$. (f) $2000 \mathrm{~s}$.

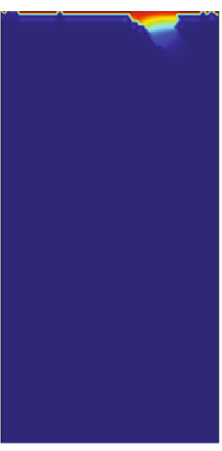

(a)

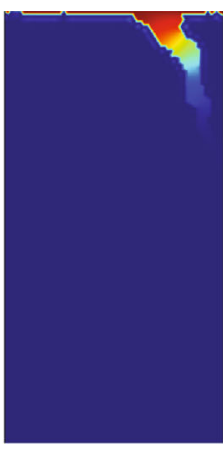

(b)

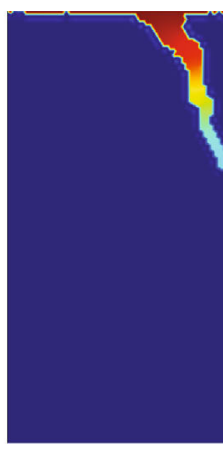

(c)

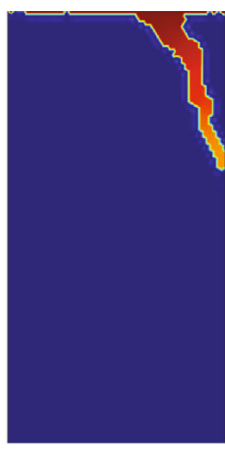

(d)

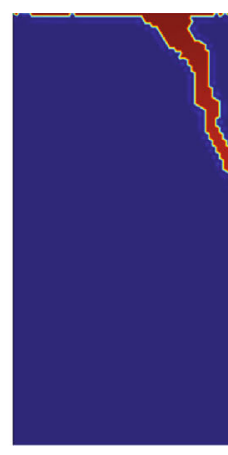

(e)

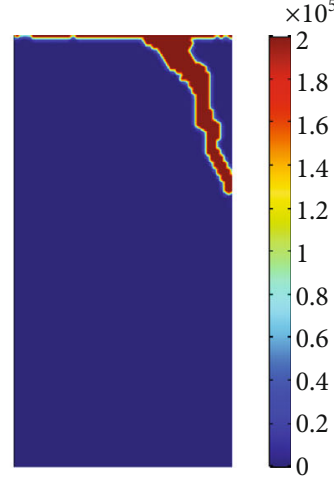

(f)

FIGURE 12: Cloud map of the variation of grouting pressure distribution with time (coal sample 2\#). (a) $t=1 \mathrm{~s}$. (b) $10 \mathrm{~s}$. (c) $50 \mathrm{~s}$. (d) $100 \mathrm{~s}$. (e) 200 s. (f) $2000 \mathrm{~s}$.

the small width in the middle position, which influences the flow velocity of the grout in the lower section of the fracture.

The variation curves of permeability of grouting coal samples with time, which are gained from the numerical simulation, are shown in Figure 15. The numerical simulation results of permeability of coal samples before and after grouting are listed in Table 4. Clearly, the overall permeability of coal samples decreases gradually, and the mean reduction amplitude is $93.5 \%$. Specifically, the initial permeability of coal sample $1 \#$ is $36.9 \mathrm{mD}$, and it decreases gradually with the increase of grouting time. The overall permeability decreases by $92.2 \%$ to $2.86 \mathrm{mD}$ at $2000 \mathrm{~s}$. The initial permeability of coal sample $2 \#$ is $6.6 \mathrm{mD}$, and it decreases gradually as the grouting continues. The overall permeability of coal sample $2 \#$ is decreased by $94.8 \%$ to $0.34 \mathrm{mD}$ at $2000 \mathrm{~s}$. According to the comparison of experimental results, the numerical simulation results conform to the experimental results, which verify the accuracy of the theoretical model.

The variation curves of the overall fracture permeability of coal samples with grouting time which are gained from numerical simulation are shown in Figure 16. Clearly, the variation trend of fracture permeability is consistent with the overall permeability of coal samples. Differently, the initial fracture permeability is higher and the reduction amplitude is larger. The fracture permeability of coal samples can be decreased by at least $99.9 \%$.

\subsection{Effects of Grouting Pressure on Permeability Reduction of} Coal Samples. Grouting pressure can influence the grouting effect significantly in the grouting process. In this section, the variation law of permeability of coal samples with time under different grouting pressures was discussed by taking 


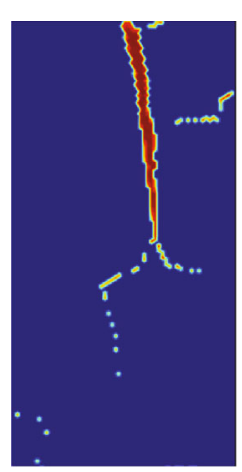

(a)

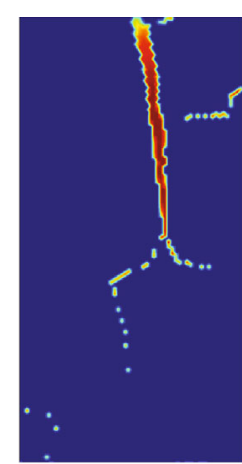

(b)

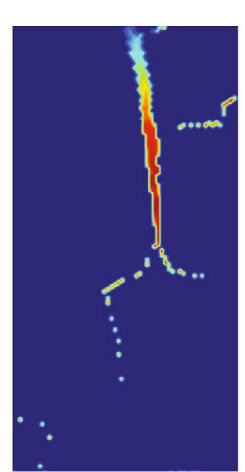

(c)

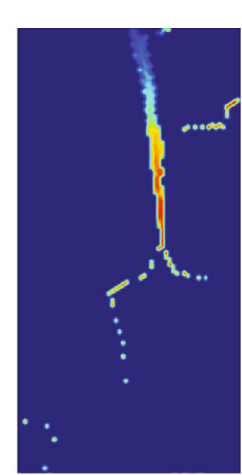

(d)

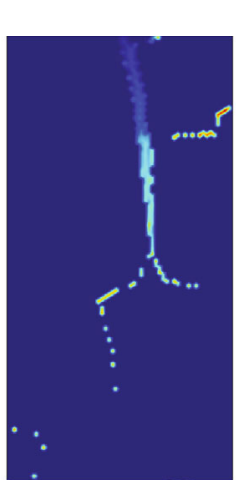

(e)

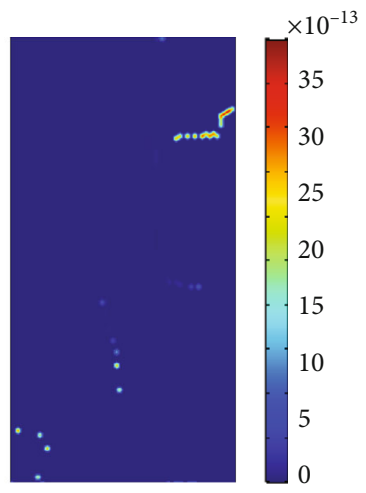

(f)

FIGURE 13: Cloud map of variation of permeability distribution with time (coal sample 1\#). (a) $t=1 \mathrm{~s}$. (b) $10 \mathrm{~s}$. (c) 50 s. (d) 100 s. (e) 200 s. (f) $2000 \mathrm{~s}$.

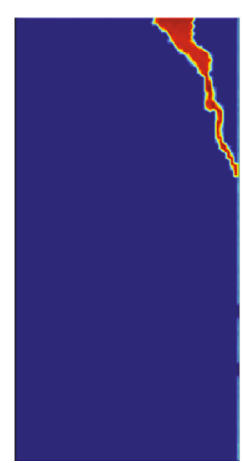

(a)

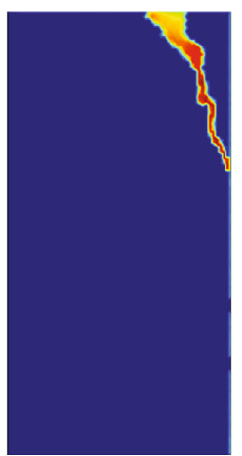

(b)

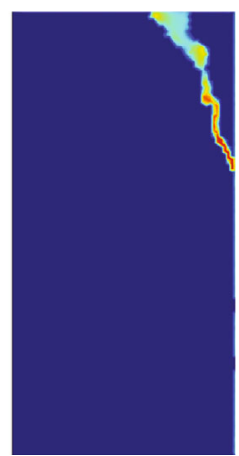

(c)

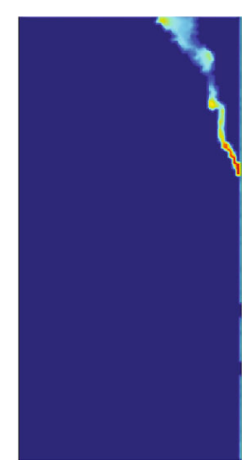

(d)

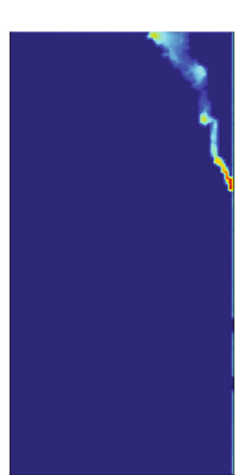

(e)

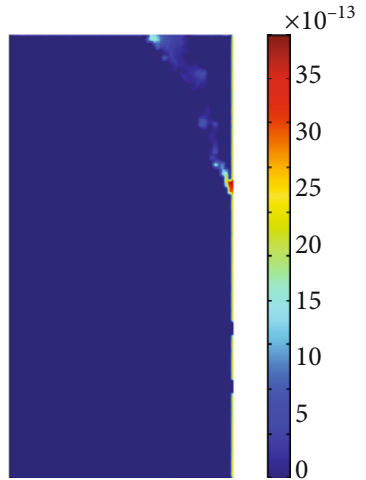

(f)

FIGURE 14: Cloud map of variation of permeability distribution with time (coal sample 2\#). (a) $t=1 \mathrm{~s}$. (b) $10 \mathrm{~s}$. (c) $50 \mathrm{~s}$. (d) $100 \mathrm{~s}$. (e) $200 \mathrm{~s}$. (f) $2000 \mathrm{~s}$.

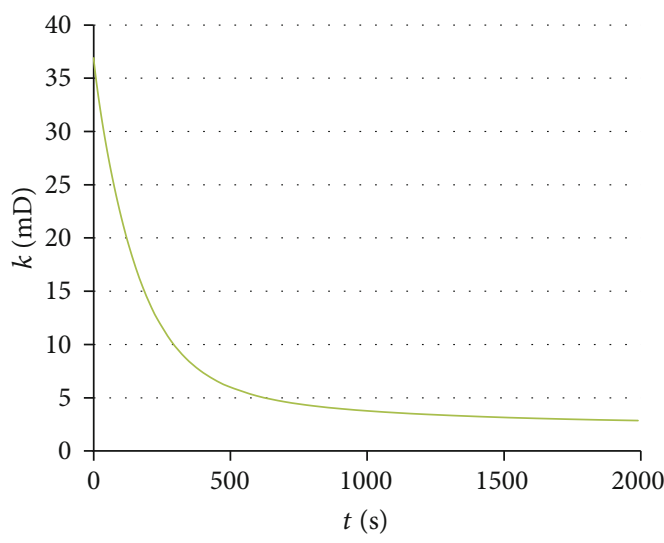

(a)

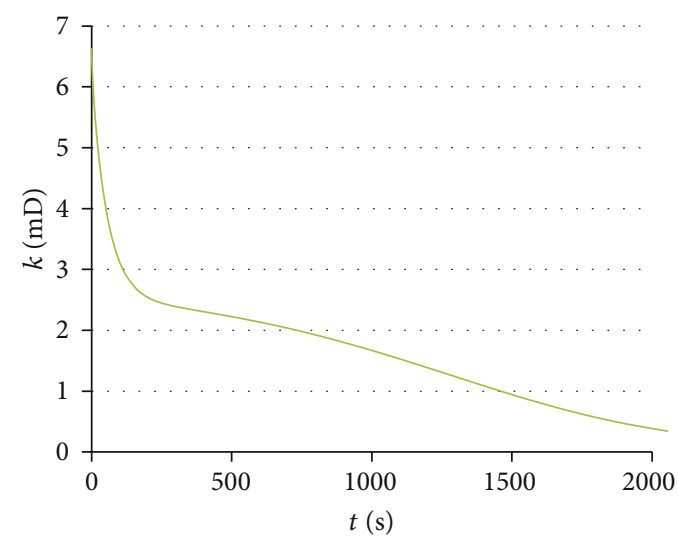

(b)

FIgURE 15: Variation curves of overall permeability of coal samples with time. (a) Coal sample 1\#. (b) Coal sample 2\#.

coal sample $1 \#$, for example. The results can provide theoretical supports to select the reasonable grouting pressure in the grouting engineering. The variation curve of permeability of coal sample $1 \#$ with time under different grouting pressures is shown in Figure 17. Clearly, permeability of coal sample
1 \# decreases by $89.6 \%$ from $37 \mathrm{mD}$ to $3.83 \mathrm{mD}$ when the grouting pressure is $0.1 \mathrm{MPa}$. When the grouting pressure is $0.2 \mathrm{MPa}$, the permeability decreases by $92.2 \%$ from $37 \mathrm{mD}$ to $2.86 \mathrm{mD}$. When the grouting pressure is $0.3 \mathrm{MPa}$, the permeability decreases by $92.5 \%$ from $37 \mathrm{mD}$ to $2.78 \mathrm{mD}$. 
TABLE 4: Numerical simulation on permeability variations of coal samples before and after grouting.

\begin{tabular}{ccccc}
\hline No. & $\begin{array}{c}\text { Initial permeability } \\
k n_{0} / \mathrm{mD}\end{array}$ & $\begin{array}{c}\text { Permeability after groutin } \\
k n_{1} / \mathrm{mD}\end{array}$ & $\begin{array}{c}\text { Reduction amplitude } \\
\left(k n_{0}-k n_{1}\right) / k n_{0}\end{array}$ & $\begin{array}{c}\text { Error between numerical simulation and experiment } \\
\%\end{array}$ \\
\hline 1 & 36.9 & 2.86 & $92.2 \%$ & $0.86 \%$ \\
2 & 6.6 & 0.34 & $94.8 \%$ & $0.73 \%$ \\
\hline
\end{tabular}

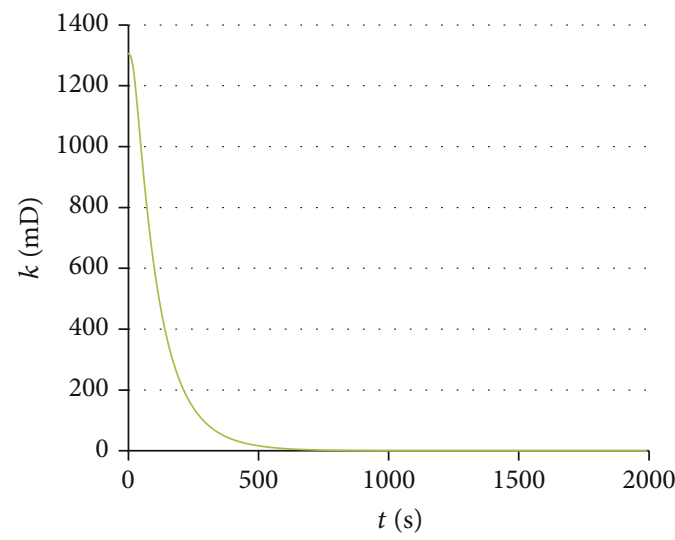

(a)

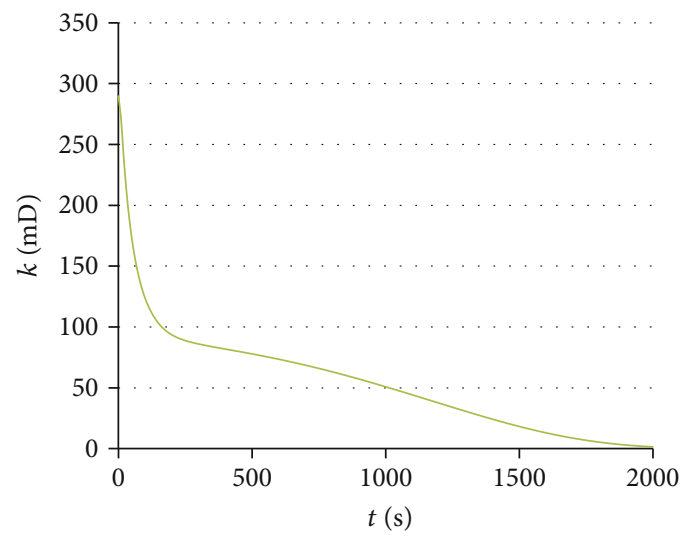

(b)

FIgURE 16: Variation curves of fracture permeability of coal samples with time. (a) Coal sample 1\#. (b) Coal sample 2\#.

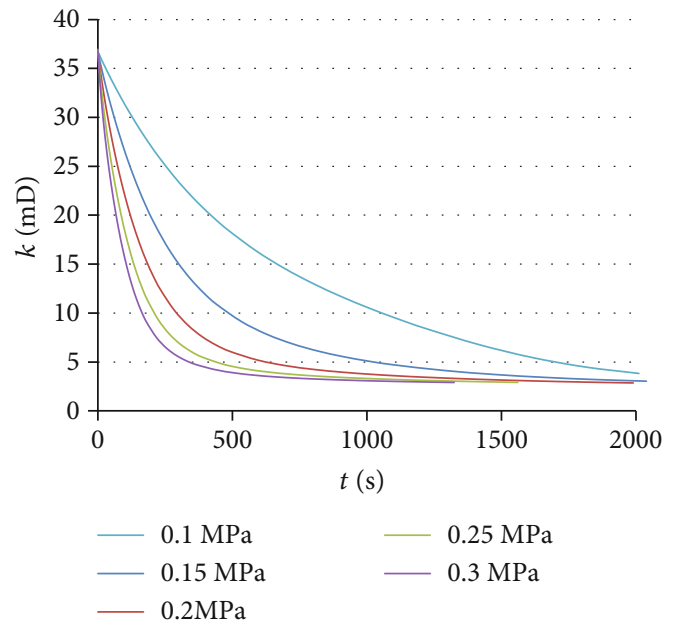

FIGURE 17: Variation curves of permeability of coal samples under different grouting pressures.

Obviously, the variation velocity of permeability of coal samples increases significantly with the grouting pressure when it is lower than $0.25 \mathrm{MPa}$. However, the variation curves of permeability of coal samples are almost consistent when the grouting pressure exceeds $0.25 \mathrm{MPa}$. In a word, the optimal grouting pressure of coal samples under this condition is about $0.25 \mathrm{MPa}$.

\section{Discussions}

Disclosing leakage stoppage and permeability reduction mechanism of grouting in fractured coal masses has important theoretical significance to strengthen the borehole seal- ing effect during gas extraction. Since existing theoretical studies hardly consider the variation of fracture and permeability of coal and rock masses caused by the deposition of grouting particles and it is difficult to describe the research status of motion law of grout accurately due to the uncertain initial fracture distribution in the numerical simulation study, authors prepared a new coal-based grouting material and tested the parameters of this grouting material (e.g., viscosity). Moreover, a theoretical grouting model of coal fracture filling with consideration of the flowing of grout and deposition of grouting particles was built up. A "visual" analysis of fracture structures in coal masses was realized by industrial CT scanning. The leakage stopping and permeability reduction mechanism of coal mass is investigated by using a numerical simulation software COMSOL. Research conclusions provide references to the quantitative analysis of the motion law of grouting particles and strengthening the borehole sealing effect for gas extraction. However, grout deposition and fracture filling involve relatively complicated physical and chemical processes. For instance, the chemical properties of grouting materials may change with time and the deposited particles can be changed into suspending particles again. In this study, the deposition process was simplified, and key attentions were paid to the physical outcomes of fracture filling by deposited grouting particles. Secondly, CT scanning and observation analysis of the whole grouting process are impossible due to limitations of experimental conditions. This study only carried out CT scanning and permeability test of coal samples at the initial state and after the grouting, but the "visual" experiment over the whole grouting process still needs improvement and updating of experimental means. In addition, this study is still under laboratory conditions and scale. The diffusion law and blocking 
mechanism of grout under engineering sale and complicated conditions are still needed.

\section{Conclusions}

In this study, a new coal-based grouting material is prepared, and its parameters such as viscosity are tested. A theoretical grouting model of the coal fracture filling with consideration of the flowing of the grout and the deposition of grouting particles is constructed. The leakage stoppage and the permeability reduction mechanism of the coal mass is investigated by using a numerical simulation software COMSOL. Some major conclusions can be drawn:

(1) Fractured coal masses are viewed as a fractured medium. With consideration of the deposition of grouting particles, the mass conservation equation of grouting particles, grout flow equation, and fracture evolutionary equation are deduced. Besides, a grout mass variable seepage model of the leakage stoppage and permeability reduction of fractured coal masses is constructed. This lays a theoretical base to disclose the leakage stoppage and permeability reduction mechanism of the grouting in fractured coal masses

(2) The permeability of fractured coal samples before and after the grouting is tested by an experiment. It was found that the proposed coal-based grouting materials can fill in coal fractures completely, thus significantly decreasing the permeability after the grouting. This proves that the coal-based grouting materials can block fractures significantly

(3) The model is reconstructed based on the real-time industrial CT scan of fractures, and CT scanning images after the reconstruction are input into the numerical simulation software COSMOL by using the independently compiled MATLAB. The whole process of the grout flowing and the fracture filling is simulated, getting the variation laws of the permeability of coal samples. Moreover, the reasonable grouting pressure of coal samples is analyzed. Numerical simulation results conform well with the CT scanning distribution of coal-based grouting materials and the permeability variation in coal samples. This further verifies the reliability of the proposed theoretical model.

\section{Data Availability}

The data used to support the findings of this study are included within the article.

\section{Conflicts of Interest}

The authors declare that they have no conflicts of interest.

\section{Acknowledgments}

This project is supported by the Natural Science Foundation of Henan (No. 202300410182), the National Natural Science Foundation of China (No. 51904095, U1704129, 51774110, and 51774118), the Scientific and Technological Projects of Henan Province (No. 202102310220), and the Plan of Key Scientific Research Projects of Colleges and Universities in Henan Province (No. 20A620001).

\section{References}

[1] C. Ö. Karacan, M. Cotè, S. Phipps, and F. A. Ruiz, "Coal mine methane: A review of capture and utilization practices with benefits to mining safety and to greenhouse gas reduction," International Journal of Coal Geology, vol. 86, no. 2-3, pp. 121-156, 2011.

[2] B. Yu, C. Su, and D. Wang, "Study of the features of outburst caused by rock cross-cut coal uncovering and the law of gas dilatation energy release," International Journal of Mining Science and Technology, vol. 25, no. 3, pp. 453-458, 2015.

[3] L. Wang and Y. P. Cheng, "Drainage and utilization of Chinese coal mine methane with a coal-methane co- exploitation model: analysis and projections," Resources Policy, vol. 37, no. 3, pp. 315-321, 2012.

[4] J. He and K. Dong, "Research on rational sealing depth of gas drainage borehole in large section roadway," China Coal, vol. 40, no. 2, pp. 101-104, 2014.

[5] Z. Ge, Y. Lu, J. Tang, B. Xia, and X. Mei, "Optimization and application of sealing material and sealing length for hydraulic fracturing borehole in underground coal mines," Arabian Journal of Geosciences, vol. 8, no. 6, article 1488, pp. 34773490, 2015.

[6] S. Li, Q. Zhang, Q. Zhang, and R. Liu, "Protection against water or mud inrush in tunnels by grouting: a review," Journal of Rock Mechanics and Geotechnical Engineering, vol. 8, no. 5, pp. 753-766, 2016.

[7] J. Y. Rafi and H. Stille, "Basic mechanism of elastic jacking and impact of fracture aperture change on grout spread, transmissivity and penetrability," Tunnelling and Underground Space Technology, vol. 49, pp. 174-187, 2015.

[8] G. Gustafson, J. Claesson, and Å. Fransson, "Steering parameters for rock grouting," Journal of Applied Mathematics, vol. 2013, Article ID 269594, 9 pages, 2013.

[9] Z. Zhou, X. Du, Z. Chen, and Y. Zhao, "Grouting diffusion of chemical fluid flow in soil with fractal characteristics," Journal of Central South University, vol. 24, no. 5, pp. 1190-1196, 2017.

[10] Y. E. Fei, C. Zhi, and G. O. U. Chang-fei, "Back-filled grouting compaction model of shield tunnel based on spherical cavity expansion," Journal of Traffic and Transportation Engineering, vol. 14, no. 1, pp. 35-42, 2014.

[11] X. F. Liu, J. G. Wang, K. Huang, and F. Li, "Experimental study on dynamic water grouting of modified water-soluble polyurethane," KSCE Journal of Civil Engineering, vol. 23, no. 9, pp. 3897-3906, 2019.

[12] W. H. Baker, "Planning and performing structural chemical grouting," American Society of Civil Engineers, vol. 1, 2010.

[13] C. Baker-Muler, Comments on paper rock stabilization in rock mechanics, Springer-Verlag, New York, 1974.

[14] W. Q. Mu, L. C. Li, T. H. Yang, G. Yu, and Y. Han, "Numerical investigation on a grouting mechanism with slurry-rock 
coupling and shear displacement in a single rough fracture," Bulletin of Engineering Geology and the Environment, vol. 78, no. 8, pp. 6159-6177, 2019.

[15] F. Xiao, Z. Y. Zhao, and H. M. Chen, "A simplified model for predicting grout flow in fracture channels," Tunnelling and Underground Space Technology, vol. 70, pp. 11-18, 2017.

[16] X. L. Li, D. Jin, F. M. Wang, Y. H. Zhong, and B. Zhang, "Diffusion model of an ideal expansible grout in single fracture," Chinese Journal of Rock Mechanics and Engineering, vol. 37, no. 5, pp. 1207-1217, 2018.

[17] A. Draganović and H. Stille, "Filtration and penetrability of cement-based grout: study performed with a short slot," Tunnelling and Underground Space Technology, vol. 26, no. 4, pp. 548-559, 2011.

[18] Y. Ping and S. Xueqing, "Single fracture grouting numerical simulation based on fracture roughness in hydrodynamic environment," Electronic Journal of Geotechnical Engineering, vol. 20, pp. 59-67, 2015.

[19] O. Saeidi, H. Stille, and S. R. Torabi, "Numerical and analytical analyses of the effects of different joint and grout properties on the rock mass groutability," Tunnelling and Underground Space Technology, vol. 38, no. 38, pp. 11-25, 2013.

[20] W. Ruan, "Spreading model of grouting in rock mass fissures based on time-dependent behavior of viscosity of cementbased grouts," Chinese Journal of Rock Mechanics and Engineering, vol. 24, no. 15, pp. 2709-2714, 2005.

[21] Q. Zhang, L. Zhang, X. Zhang, R. T. Liu, M. T. Zhu, and D. Z. Zheng, "Grouting diffusion in a horizontal crack considering temporal and spatial variation ofviscosity," Chinese Journal of Rock Mechanics and Engineering, vol. 34, no. 6, pp. 11981210, 2015.

[22] R. S. Yang, H. J. Xue, D. M. Guo et al., "Laboratory grouting experiment based CT analysis of grouted soft rocks in deep mines," Journal of China Coal Society, vol. 41, no. 2, pp. 345351, 2016.

[23] Y. Yu, Experimental study on mechanical properties and permeability of coal with grouting reinforcement, Harbin:Heilongjiang University of Science and Technology, 2015.

[24] L. Ning, Z. Ping, and Y. Jianwen, "Numerical modeling of grouting in geoengineering," Chinese Journal of Rock Mechanics and Engineering, vol. 21, no. 3, pp. 326-330, 2002.

[25] Q. Li, W. Z. Chen, J. Q. Yuan, Y. X. Wang, and H. Wan, "Evaluation of grouting reinforcement effect for karst filling medium based on seepage-erosion theory," Chinese Journal of Rock Mechanics and Engineering, vol. 39, no. 3, pp. 1-9, 2020.

[26] L. I. U. Rentai, Z. Zhuo, L. I. Shucai, and Z. Qingsong, "Preexcavation grouting to prevent water inflow of jointed rock in underground construction," Journal of Southwest Jiaotong University, vol. 54, no. 1, pp. 48-54, 2019.

[27] G. X. Zhu, Q. S. Zhang, X. Feng et al., "Study on the filtration mechanism in permeation grouting using the particle deposition probability model," Advanced Engineering Sciences, vol. 52, no. 5, pp. 125-135, 2020.

[28] L. Sun, G. Grasselli, Q. Liu, and X. Tang, "Coupled hydromechanical analysis for grout penetration in fractured rocks using the finite-discrete element method," International Journal of Rock Mechanics and Mining Sciences, vol. 124, article 104138, 2019.

[29] Z. Xu, X. Zhou, G. Gao, X. Feng, and C. Liu, "Full-scale physical modelling of fissure grouting in deep underground rocks,"
Tunnelling and Underground Space Technology, vol. 89, pp. 249-261, 2019.

[30] S. Berrone, C. Canuto, S. Pieraccini, and S. Scialò, "Uncertainty quantification in discrete fracture network models: stochastic fracture transmissivity," Computers \& Mathematics with Applications, vol. 70, no. 4, pp. 603-623, 2015.

[31] X. Han, J. Chen, Q. Wang, Y. Li, W. Zhang, and T. Yu, “A 3D fracture network model for the undisturbed rock mass at the Songta Dam Site based on small samples," Rock Mechanics \& Rock Engineering, vol. 49, no. 2, pp. 611-619, 2016.

[32] M. Li, S. Han, S. Zhou, and Y. Zhang, "An improved computing method for $3 \mathrm{D}$ mechanical connectivity rates based on a polyhedral simulation model of discrete fracture network in rock masses," Rock Mechanics \& Rock Engineering, vol. 51, no. 6, article 1423, pp. 1789-1800, 2018.

[33] C. Yan and H. Zheng, "Three-dimensional hydromechanical model of hydraulic fracturing with arbitrarily discrete fracture networks using finite-discrete element method," International Journal of Geomechanics, vol. 17, no. 6, article 04016133, 2017.

[34] S. Deng, X. Wang, J. Yu, Y. Zhang, Z. Liu, and Y. Zhu, "Simulation of grouting process in rock masses under a dam foundation characterized by a 3D fracture network," Rock Mechanics \& Rock Engineering, vol. 51, no. 6, article 1436, pp. 1801-1822, 2018.

[35] Q. Liu, X. Cui, and C. Zhang, "Permeability reduction model of particles deposit in porous medium considering changeable porosity," Chinese Journal of Rock Mechanics and Engineering, vol. 35, pp. 3308-3314, 2016.

[36] L. Huawei, The study on the penetration property of red mud filtrate and transport process of contaminant, BEIJING JIAOTONG UNIVERSITY, BeiJing, 2015.

[37] F. Ye, X. Han, and N. Qin, "Displacement infiltration diffusion model of binghamian grouts as backfill grouting of shield tunne," Journal of Tongji University. Natural Science, vol. 47, no. 12 , pp. 1720-1726, 2019.

[38] W. Jianping, D. Wang, and W. Le, "Comparison of permeability between two kinds of loaded coal containing gas samples," Journal of China Coal Society, vol. 38, no. S1, pp. 93-99, 2013.

[39] D. Ma, H. Duan, X. Cai, and Z. Li, "A global optimizationbased method for the prediction of water inrush hazard from mining floor," Water, vol. 10, no. 11, pp. 1-18, 2018.

[40] D. Ma, J. Wang, and Z. Li, "Effect of particle erosion on mining-induced water inrush hazard of karst collapse pillar," Environmental Science and Pollution Research International, vol. 26, no. 19, pp. 19719-19728, 2019.

[41] W. Jianping, W. Le, and W. Dengke, "Experimental study of moisture content influences on permeability of coal containing gas," Journal of China Coal Society, vol. 39, no. 1, pp. 97-103, 2014.

[42] Y. Xue, P. G. Ranjith, F. Dang et al., "Analysis of deformation, permeability and energy evolution characteristics of coal mass around borehole after excavation," Natural Resources Research, vol. 29, no. 5, pp. 3159-3177, 2020.

[43] J. Liu, X. Liang, Y. Xue, K. Yao, and Y. Fu, "Numerical evaluation on multiphase flow and heat transfer during thermal stimulation enhanced shale gas recovery," Applied Thermal Engineering, vol. 178, article 115554, 2020. 